Sports

Elsevier Editorial System(tm) for Science \&

Manuscript Draft

Manuscript Number: SCISPO-D-16-00011R1

Title: A wearable sensor to monitor localized sweat rate as support tool for monitoring athletes' performances

Article Type: Full Length Article

Keywords: Sweat rate; sports performance; personalized training; wearable sensor; hydration.

Mots clés

Taux de sudation; performance sportive; entraînement personnalisé;

capteur portable; hydration.

Corresponding Author: Dr. Pietro Salvo, Ph.D.

Corresponding Author's Institution: National Council of Research

First Author: Pietro Salvo, Ph.D.

Order of Authors: Pietro Salvo, Ph.D.; Alessandro Pingitore, MD, Ph.D.; Alessandro Barbini, M.Sc.; Fabio Di Francesco, Ph.D.

Abstract: Objectives

We developed a wearable sensor for the real time measurement of sweat rate in localized areas of the human body. This sensor represents the first step in the development of a wearable sensor network capable to estimate the global sweat rate via an ad hoc algorithm. Such device would be used to monitor athletes' hydration status during training and improve their performances.

Equipment and Methods

For this study, we tested our sensor on thirteen football players during a cycling test on a cycle ergometer. The sweat rate sensor was compared to a medical device that, although measuring a different physiological process, provides discrete data based on the same working principle, i.e. the diffusion of the water vapour emitted from the skin.

Results

Our sensor has a working range up to $400 \mathrm{~g} / \mathrm{m} 2 \cdot \mathrm{h}$. The statistical analysis and the Bland-Altman plot proved that our sensor is comparable to the medical device used as gold standard. At low sweat rate, the bias is 3.4 $\mathrm{g} / \mathrm{m} 2 \cdot \mathrm{h}$ with a standard deviation of $7.6 \mathrm{~g} / \mathrm{m} 2 \cdot \mathrm{h}$. At maximum sweat rates, the bias is $2.3 \mathrm{~g} / \mathrm{m} 2 \cdot \mathrm{h}$ with a standard deviation $6.9 \mathrm{~g} / \mathrm{m} 2 \cdot \mathrm{h}$. The pvalues for the Bland-Altman plots at low and maximum sweat rate $(0.1331$ and 0.2477 obtained by Kolmogorov-Smirnov test, respectively) allow the hypothesis that there is a significant difference between our sweat rate sensor and the medical device to be rejected.

Conclusion

We presented a prototype of a wearable sweat rate sensor for localized measurements. The trials on thirteen athletes proved that the performance 
of our sensor is comparable to that of a commercial medical device. This sweat rate sensor can provide valuable information on athletes' hydration status.

Résumé

Objectifs

Nous avons développé un capteur portable pour mesurer le taux de sudation en temps réel dans des zones localisées du corps humain. Ce capteur pourrait conduire à un réseau portable qui peut être pour estimer le taux de sueur global via un algorithme ad hoc pour surveiller l'état d'hydratation des athlètes lors de l'entraînement afin d'améliorer leurs performances.

Matériel et Méthodes

Pour cette étude, nous avons testé notre capteur sur treize joueurs de foot pendant un test de vélo sur une bicyclette ergométrique. Le capteur de vitesse de la sueur a été comparé à un dispositif médical qui, bien que mesurant un processus physiologique différent, fournit des données discrètes basées sur le même principe de fonctionnement, à savoir la diffusion de la vapeur d'eau émise par la peau.

\section{Résultats}

Notre capteur a une capacité de fonctionnement jusqu'à $400 \mathrm{~g} / \mathrm{m} 2 \cdot \mathrm{h}$. L'analyse statistique et graphique de Bland-Altman a prouvé que notre capteur est comparable au dispositif médical utilisé comme référence. Avec un taux de sudation bas, le biais est de $3.4 \mathrm{~g} / \mathrm{m} 2 \cdot \mathrm{h}$ avec écart type de $7.6 \mathrm{~g} / \mathrm{m} 2 \cdot \mathrm{h}$. Avec un taux de sudation maximal, le biais est de 2.3 $\mathrm{g} / \mathrm{m} 2 \cdot \mathrm{h}$ avec un écart type de $6.9 \mathrm{~g} / \mathrm{m} 2 \cdot \mathrm{h}$. Les $\mathrm{p}$-values pour les graphiques de Bland-Altman à des taux de sudation faible et maximum (0.1331 et 0.2477, respectivement) obtenues par les tests de Kolmogorov-Smirnov, permettent de rejeter l'hypothèse selon laquelle il existe une différence significative entre notre capteur de vitesse de la sudation et le dispositif médical.

Conclusion

Nous avons présenté un prototype de capteur de vitesse de sudation portable pour les mesures localisées. Cet essai sur treize athlètes a montré que la performance de notre capteur est comparable à celle du dispositif médical commercialisé. Ce capteur de taux de sudation peut fournir des informations précieuses sur l'état d'hydratation des athlètes. 


\section{Article title}

A wearable sweat rate sensor to monitor the athletes' performance during training

\section{Authors}

P. Salvo ${ }^{1 *}$, A. Pingitore ${ }^{2}$, A. Barbini ${ }^{3}$, F. Di Francesco ${ }^{1,4}$

${ }^{1}$ Department of Chemistry and Industrial Chemistry, University of Pisa, Via Moruzzi 13, 56124, Pisa, Italy.

${ }^{2}$ Institute of Clinical Physiology, National Research Council, Via Moruzzi 1, 56124, Pisa, Italy.

${ }^{3}$ National Institute of Optics, National Research Council, Via Moruzzi 1, 56124, Pisa, Italy.

${ }^{4}$ Research Center "E.Piaggio", University of Pisa, Largo Lazzarino 1, 56122, Pisa, Italy.

*Corresponding author

P. Salvo, Department of Chemistry and Industrial Chemistry, University of Pisa, Via Moruzzi 13, 56124, Pisa, Italy.

Email: pietro.salvo@gmail.com

Tel.: +390502219253

Fax: +390502220673 


\section{Summary}

2

3 Objectives

4 We developed a wearable sensor for the real time measurement of sweat rate in localized areas of 5 the human body. This sensor represents the first step in the development of a wearable sensor 6 network capable to estimate the global sweat rate via an ad hoc algorithm. Such device would be 7 used to monitor athletes' hydration status during training and improve their performances.

9 Equipment and Methods

10 For this study, we tested our sensor on thirteen football players during a cycling test on a cycle 11 ergometer. The sweat rate sensor was compared to a medical device that, although measuring a 12 different physiological process, provides discrete data based on the same working principle, i.e. the 13 diffusion of the water vapour emitted from the skin.

15 Results

16 Our sensor has a working range up to $400 \mathrm{~g} / \mathrm{m}^{2} \cdot \mathrm{h}$. The statistical analysis and the Bland-Altman 17 plot proved that our sensor is comparable to the medical device used as gold standard. At low sweat 18 rate, the bias is $3.4 \mathrm{~g} / \mathrm{m}^{2} \cdot \mathrm{h}$ with a standard deviation of $7.6 \mathrm{~g} / \mathrm{m}^{2} \cdot \mathrm{h}$. At maximum sweat rates, the 19 bias is $2.3 \mathrm{~g} / \mathrm{m}^{2} \cdot \mathrm{h}$ with a standard deviation $6.9 \mathrm{~g} / \mathrm{m}^{2} \cdot \mathrm{h}$. The p-values for the Bland-Altman plots at 20 low and maximum sweat rate $(0.1331$ and 0.2477 obtained by Kolmogorov-Smirnov test, 21 respectively) allow the hypothesis that there is a significant difference between our sweat rate 22 sensor and the medical device to be rejected.

24 Conclusion

25 We presented a prototype of a wearable sweat rate sensor for localized measurements. The trials on 26 thirteen athletes proved that the performance of our sensor is comparable to that of a commercial 27 medical device. This sweat rate sensor can provide valuable information on athletes' hydration 28 status.

\section{Résumé}

Objectifs 
33 Nous avons développé un capteur portable pour mesurer le taux de sudation en temps réel dans des

34 zones localisées du corps humain. Ce capteur pourrait conduire à un réseau portable qui peut être

35 pour estimer le taux de sueur global via un algorithme ad hoc pour surveiller l'état d'hydratation des

36 athlètes lors de l'entraînement afin d'améliorer leurs performances.

Matériel et Méthodes

39 Pour cette étude, nous avons testé notre capteur sur treize joueurs de foot pendant un test de vélo sur 40 une bicyclette ergométrique. Le capteur de vitesse de la sueur a été comparé à un dispositif médical 41 qui, bien que mesurant un processus physiologique différent, fournit des données discrètes basées 42 sur le même principe de fonctionnement, à savoir la diffusion de la vapeur d'eau émise par la peau.

44 Résultats

45 Notre capteur a une capacité de fonctionnement jusqu'à $400 \mathrm{~g} / \mathrm{m}^{2} \cdot \mathrm{h}$. L'analyse statistique et 46 graphique de Bland-Altman a prouvé que notre capteur est comparable au dispositif médical utilisé 47 comme référence. Avec un taux de sudation bas, le biais est de $3.4 \mathrm{~g} / \mathrm{m}^{2} \cdot \mathrm{h}$ avec écart type de 7.6 $48 \mathrm{~g} / \mathrm{m}^{2} \cdot \mathrm{h}$. Avec un taux de sudation maximal, le biais est de $2.3 \mathrm{~g} / \mathrm{m}^{2} \cdot \mathrm{h}$ avec un écart type de 6.9 $49 \mathrm{~g} / \mathrm{m}^{2} \cdot \mathrm{h}$. Les $p$-values pour les graphiques de Bland-Altman à des taux de sudation faible et 50 maximum (0.1331 et 0.2477 , respectivement) obtenues par les tests de Kolmogorov-Smirnov, 51 permettent de rejeter l'hypothèse selon laquelle il existe une différence significative entre notre 52 capteur de vitesse de la sudation et le dispositif médical.

54 Conclusion

55 Nous avons présenté un prototype de capteur de vitesse de sudation portable pour les mesures 56 localisées. Cet essai sur treize athlètes a montré que la performance de notre capteur est comparable 57 à celle du dispositif médical commercialisé. Ce capteur de taux de sudation peut fournir des 58 informations précieuses sur l'état d'hydratation des athlètes.

\section{Keywords}

61 Sweat rate; sports performance; personalized training; wearable sensor, hydration.

\section{Mots clés}

64 Taux de sudation; performance sportive; entraînement personnalisé; capteur portable ; hydration. 


\section{Introduction}

The production and evaporation of sweat from the skin's surface is essential to regulate temperature in the human body and maintain homeostasis [1]. Sweat occurs with the activation of eccrine glands and the rate depends on the emitted amount per gland [2]. Eccrine glands are unevenly distributed on the skin and their number ranges between about 1.6 and 4 million. The palms of hands and the soles of feet have the highest density $\left(600-700\right.$ glands $\left./ \mathrm{cm}^{2}\right)$, whereas other parts of the human body have a density that is less than one third lower, e.g. 108 glands $/ \mathrm{cm}^{2}$ on the forearm and 181 glands $/ \mathrm{cm}^{2}$ on the forehead [3]. At $25{ }^{\circ} \mathrm{C}$ and a relative humidity of $50 \%$, the average sweat rate in adults is about $500-700 \mathrm{~mL} /$ day with a maximum of $1.4 \mathrm{~L} / \mathrm{h}$ or $20 \mathrm{~nL} / \mathrm{min}$ per gland $[1,3,4]$. Although exceptional values of sweat rates are possible, e.g. $1 \mathrm{~L}$ for $15 \mathrm{~min}$ in saunas or more than $3 \mathrm{~L} / \mathrm{h}$ during preparation for a marathon $[3,5]$, the human body can only sustain high sweat rates for a short period. Despite its crucial role in thermoregulation, there is a side effect of sweat production. During sweating, the body loses fluids that need to be replaced to maintain the correct functionality of the physiological processes inside the human organism. In fact, sweat consists of about $99 \%$ water and about $1 \%$ electrolytes, mainly sodium, chloride and potassium [6]. Therefore, especially during exercise or intense training, there is a concrete risk of dehydration $[7,8]$. Although there are athletes who can tolerate fluid losses of 4\%-5\% of body mass, in normal subjects, values between $1 \%$ and $2 \%$ of body weight already start to alter the normal physiological conditions [9]. Higher values of dehydration affect the cardiovascular system, causing for example heat cramps or heatstroke [10].

The electrolytes lost during sweating are indispensable to preserve and maintain blood pressure, plasma volume, the transmission of nerve impulses and normal cell activities [11-13]. The correct replenishment prevents abnormal physiological conditions, which can also be potentially life threatening. During a competition, athletes can only rely on their feelings and experience to match their physical efforts to their physical conditions. Hence, knowing their sweat rate values would help athletes in achieving optimum performance while avoiding possible health complications.

Measuring the sweat rate is challenging and currently there is no technique to determine sweat rate outside controlled laboratories during the subject's normal life or training [14]. In the iodine starch method, some iodine powder is sprayed on the skin. In contact with sweat, the colour of the powder 
turns dark purple [15]. However, this method can only be used for assessing the presence of sweat. The wash-down method involves the construction of a plastic frame that supports a large plastic bag within which the subject exercises with a cycle ergometer. Before the beginning of the exercise, the subject and the bag are washed with deionized water. When the exercise is completed, the subject and the bag are washed with water containing ammonium sulphate, which is absent in sweat. The sweat loss is calculated from the change in body mass, whereas the volume of sweat is calculated from the dilution of the ammonium sulphate [16]. This method is unsuitable for long-term

104 measurements, impractical outside specialized laboratories and can only provide an estimation of 105 the total sweat loss.

106 The current research is focused on methods that can locally measure sweat rate in different body 107 areas and supply data to an algorithm capable to estimate the global sweat rate. Given that 108 electrolytes are present in sweat, an approach is to measure the electrical impedance to quantify the 109 sweat loss $[17,18]$. Due to the miniaturization of the electronic devices, this method can lead to the 110 production of wearable devices. However, it relies on the measurement of skin impedance, which 111 can in fact be altered by artefacts due to the electrodes [19] and other factors such as strong 112 emotions, startling events, stress-induced changes and ambient humidity $[3,20]$.

113 Other common methods consist of weighing patches placed on the subject's skin before and after 114 exercise $[10,21]$. With this approach, the sweat rate can only be calculated by applying the patches 115 on the subject's skin at different times. The sample time is high and there is a risk of blocking the 116 sweat glands ducts or modifying the microclimate close to the skin.

117 WR Medical Electronics markets a non-wearable device, Q-Sweat, for measuring the sweat rate. 118 However, Q-Sweat is mainly intended for the quantitative sudomotor axon reflex test (QSART) to 119 assess the functionality of the nerve fibres that control sweating.

120 A-wearable sensor that measure the local sweat rate by means of image analysis was described by 121 Matzeu et al. [22]. The sweat flowed in a graduated spiral pattern and, with a sequence of 122 photographs of the spiral taken by a non-wearable camera at different times, the level of sweat rate 123 could be deduced.

124 We described a prototype of a wearable sweat rate sensor in a previous work [23]. This sensor was 125 based on the open-chamber method to measure the water vapour emitted from the skin [24, 25] and 126 included two humidity sensors placed at different heights in two pockets created with a plastic 127 gasket and two fabric nets. The preliminary results were promising, but the sensor had some typical 128 limitations of prototypes. The correct partial pressure values of water vapour used to calculate the 129 sweat rate could only be obtained if temperatures at the two different heights were known. The light 
130 and flexible sensor packaging made it difficult to keep a fixed distance between the humidity

131 sensors. Furthermore, the read-out digital circuitry connected to the capacitive humidity sensors was 132 complex.

133 In this paper, we present a different prototype for the local measurement of sweat rate in different 134 body areas, more easy-to-use and efficient than the current measurement methods.

\section{Materials and Methods}

The open-chamber method is derived from Fick's first law of diffusion to calculate the sweat rate. The sweat rate is defined as the flow of water vapour emitted from the skin. The flow of water vapour, $\mathrm{F}\left(\mathrm{g} / \mathrm{m}^{2} \cdot \mathrm{h}\right)$, is proportional to the rate of change in the partial pressure of water vapour close to the skin's surface, $\Delta \mathrm{P} / \Delta \mathrm{x}$, calculated at two fixed positions, i.e. $\mathrm{F} \propto \mathrm{A} \cdot \frac{\Delta \mathrm{P}}{\Delta \mathrm{x}}$, where $\mathrm{A}$ is the area of 142 vapour emission and $\mathrm{x}$ is the distance from the water vapour-emitting surface. The proportionality 143 coefficient can be found by calibrating the sensor. $\mathrm{P}_{\mathrm{SAT}}$ can be calculated by Antoine's formula:

$144 \log _{10} \mathrm{P}_{\mathrm{SAT}}=\mathrm{A}-\frac{\mathrm{B}}{\mathrm{C}+\mathrm{T}}$

where $\mathrm{T}$ is the temperature $\left({ }^{\circ} \mathrm{C}\right)$ and $\mathrm{A}, \mathrm{B}$ and $\mathrm{C}$ are substance-specific coefficients. For water between 1 and $100{ }^{\circ} \mathrm{C}, \mathrm{A}=8.07131{ }^{\circ} \mathrm{C}, \mathrm{B}=1730.63{ }^{\circ} \mathrm{C}$ and $\mathrm{C}=233.426{ }^{\circ} \mathrm{C}$. It follows that the measurement of sweat rate consists in evaluating a humidity gradient and temperatures at two different locations. Water vapour pressure is equal to the product of relative humidity (RH) and saturation pressure $\left(\mathrm{P}_{\mathrm{SAT}}\right)$, i.e. $\mathrm{P}=\mathrm{P}_{\mathrm{SAT}} \cdot \mathrm{RH}$.

153 Figure 1a shows the PTFE cylinder placed inside the adapter. Two Velcro ${ }^{\circledR}$ strips were inserted into 154 two rectangular openings of the adapter, so that the sensor could be easily kept still on the subject's 155 arm. The base of the adapter was $3 \mathrm{~mm}$ thick, but was gradually increased until $4 \mathrm{~mm}$ at both sides 156 of the two openings, as shown in Figure 1b. This solution took into account the irregularity of the 157 body surface and improved the contact with the skin.

158 The adapter and the chamber had a slot for a tiny double-sided printed circuit board (PCB $-3.2 \mathrm{~cm}$ $159 \times 1.9 \mathrm{~cm}$ ). The humidity and temperature sensors were SHT25s (Sensirion, $3 \mathrm{~mm}$ x $3 \mathrm{~mm} \times 1.1$ $160 \mathrm{~mm}$ ). SHT25s provide calibrated and linearized signals with a digital 2-wire interface in I2C format. 
161 The resolution is up to 12 and 14 bit for humidity and temperature, respectively. Supply voltage 162 ranges from 2.1 to $3.6 \mathrm{~V}$ and the maximum power dissipation is $1 \mathrm{~mW}$ during measurement. The 163 SHT25s share the same I2C address, therefore an I2C switch (PCA9546A, Texas Instruments) was 164 added to the electronic design. In our set up, one SHT25 was placed on the PCB to be $4 \mathrm{~mm}$ from 165 the skin, and the other SHT25 at $11 \mathrm{~mm}$. The PCB bottom layer only contained resistors and 166 capacitors used to drive the digital interface. The copper tracks and the chip pins were entirely 167 protected from water vapour by a transparent passivation layer. Figure 2 shows the PCB with 168 mounted components.

169 In our system, the read-out circuitry consisted of an Arduino Pro Mini (SparkFun Electronics) 170 running at $3.3 \mathrm{~V}-8 \mathrm{MHz}$. The dimensions of the Pro Mini PCB were approximately $1.8 \mathrm{~cm} \times 3.3$ $171 \mathrm{~cm}$ x $0.8 \mathrm{~mm}$. The datalogger was an OpenLog (SparkFun Electronics, $1.9 \mathrm{~cm}$ x $1.5 \mathrm{~cm}$ x $0.4 \mathrm{~mm}$ ), 172 running at $3.3 \mathrm{~V}$ and with a slot for a micro secure digital (SD) card. Optionally, data could be 173 remotely transmitted by a tiny Bluetooth module (HM10, $3.3 \mathrm{~V}, 1.3 \times 2.8$ x $0.23 \mathrm{~cm}$, JNHuaMao 174 Technology Company). The read-out circuitry was powered by a flat rectangular lithium polymeric 175 (LiPo) battery (Unionfortune, $1400 \mathrm{~mA} \cdot \mathrm{h}, 5 \mathrm{~cm} \times 3.4 \mathrm{~cm} \times 0.8 \mathrm{~cm}$ ). Because of the relatively low 176 power consumption (15 mA at maximum with Bluetooth disabled), the battery enabled continuous 177 measurements to be run for approximately four days. The small size of the components enabled a 178 very compact read-out board to be built that could be easily fitted into a smartphone armband. In the 179 experiments, the sampling time was 2 s. Figure 3 shows an example of how the sweat rate sensor 180 can be worn.

181 The sweat rate sensor was tested on thirteen amateur healthy football players. Each player was 182 informed of the purpose and procedures involved in the study and gave a written informed consent. 183 The local Ethics Committee approved the study (protocol number 2805). The study was performed 184 on a cycle ergometer, with constant load increments of $25 \mathrm{~W}$ every minute until each player reached 185 a state of functional exhaustion where the load was stopped and the maximum sweat rate value was 186 recorded. The players' physical conditions were constantly monitored by ergospirometry and 187 spirometry. The lab allowed the tests to be performed in controlled environmental conditions at $25^{\circ}$ $188 \mathrm{C}$ and $35 \%$ relative humidity.

189 A spectral analysis of the sweat profiles showed the absence of significant noise at values higher 190 than the sampling frequency. A moving average filter with a seven-sample window was used to 191 decrease the low frequency noise. The delay introduced by the filter, i.e. $3.5 \mathrm{~s}$ equal to half of the 192 window size, was acceptable for this application. 
193 The sweat rate sensor was compared to a commercial device, the Dermalab ${ }^{\circledR}$ TEWL (Cortex 194 Technology). Dermalab ${ }^{\circledR}$ measures the transepidermal water loss due to the diffusion of water 195 vapour through the dermal and epidermal layers and is not associated with the activity of sweat 196 glands [26]. However, although related to different physiological processes, since the diffusion of 197 water vapour occurs for both transepidermal water loss and sweating, Dermalab ${ }^{\circledR}$ was used as a 198 reference since it relies on the open-chamber method described in this paper. Dermalab ${ }^{\circledR}$ is a non199 wearable device with a measurement range from 0 to $250 \mathrm{~g} / \mathrm{m}^{2} \cdot \mathrm{h}$, which is sufficient for the purpose 200 of the test described in this paper. Dermalab ${ }^{\circledR}$ consists of a handheld probe equipped with a 201 measurement head (Fig. 4). The head is put in contact with the skin and the measurement is 202 manually performed [27]. During our study, Dermalab ${ }^{\circledR}$ took between approximately $30 \mathrm{~s}$ and $60 \mathrm{~s}$ 203 to perform a measurement, with longer measurement times at higher sweat rates. Between each 204 measurement, the Dermalab ${ }^{\circledR}$ probe was on its station.

205 Calibration

206

207 The sweat rate sensor was calibrated dispensing a water droplet of $1 \mu 1$ into a PTFE cylindrical 208 well, defined as the calibration cap. As soon as the droplet is dispensed, it starts evaporating. The 209 water vapour flow rate measured by the sweat rate sensor was numerically integrated with respect 210 to time to evaluate the weight of the evaporated water. The calculated weight was then compared 211 with the true weight of the droplet to find the correction factor. We used three different cap depths, 212 i.e. 2, 4 and $5 \mathrm{~cm}$, heated at different temperatures to obtain different evaporation rates [28]. The 213 measurement range is $[6,400] \mathrm{g} / \mathrm{m}^{2} \cdot \mathrm{h}$, accuracy of $4 \mathrm{~g} / \mathrm{m}^{2} \cdot \mathrm{h}$ in the sub-range $[6,130] \mathrm{g} / \mathrm{m}^{2} \cdot \mathrm{h}$ and of $21422 \mathrm{~g} / \mathrm{m}^{2} \cdot \mathrm{h}$ for sweat rate greater than $130 \mathrm{~g} / \mathrm{m}^{2} \cdot \mathrm{h}$. Fig. 5 shows the calibration curve in $\log -\log$ scale. 215 The calibration curve follows a power trend that can be approximated linear until $200 \mathrm{~g} / \mathrm{m}^{2} \cdot \mathrm{h}$. The 216 sensor sensitivity can be derived by Fick's first law and expressed as the ratio between TEWL and $217 \Delta \mathrm{P} / \Delta \mathrm{x}$. Thus, sensitivity was $1.8\left(\mathrm{~g} / \mathrm{m}^{2} \cdot \mathrm{h} / \mathrm{mmHg} / \mathrm{m}\right)$, roughly.

\section{Results}

221 Each test consisted of three phases. Phase 1: measurement of the base sweat rate. Phase 2: the 222 volunteer reached the exhaustion peak. The maximum value of sweat rate was recorded in this 223 phase. Phase 3: recovery, when the sweat rate returned to the base value. The volunteer stopped 
224 cycling about 1 min before the end of Phase 2. On average, each volunteer cycled for about 15 min, 225 with a maximum of $20 \mathrm{~min}$.

226 Figures $6 \mathrm{a}$ and $6 \mathrm{~b}$ show the sweat rate values for the Dermalab ${ }^{\circledR}$ and our sensor in Phases 1 and 2 , 227 respectively. The average difference in the basal values, $\mathrm{D}_{\text {bas }}$, was only $3.4 \mathrm{~g} / \mathrm{m}^{2} \cdot \mathrm{h}$ with a standard 228 deviation of $7.6 \mathrm{~g} / \mathrm{m}^{2} \cdot \mathrm{h}$. Similarly, good results were obtained by comparing the maximum values 229 of sweat rate, with an average difference, $D_{\max }$, of $5.9 \mathrm{~g} / \mathrm{m}^{2} \cdot \mathrm{h}$ and a standard deviation of 3.9 $230 \mathrm{~g} / \mathrm{m}^{2} \cdot \mathrm{h}$. The maximum values were calculated in the interval of Phase 2 , where the sweat rate can be 231 assumed constant. The difference $\left|D_{\max }-D_{\text {bas }}\right|$ was negligible due to the few number of points 232 sampled by Dermalab ${ }^{\circledR}$.

233 Figure $6 \mathrm{c}$ shows an example of the cycling tests, confirming a good agreement between the 234 Dermalab $^{\circledR}$ and the sweat rate sensor. During Phase 2, the signal output showed a low frequency 235 noise around the maximum. For the sweat rate sensor, the standard deviation of the maximum 236 values was between 3 and $9.4 \mathrm{~g} / \mathrm{m}^{2} \cdot \mathrm{h}$.

237 The sweat rate base value was assumed constant during Phase 1, as seen in the example shown in 238 Fig. 6c. This statement allowed Phase 1 to be used to assess the sensor repeatability. Figure 6d 239 shows the standard deviations of the sweat rate base values calculated in Phase 1. The sweat rate 240 sensor provided a standard deviation ranging from $0.6 \mathrm{~g} / \mathrm{m}^{2} \cdot \mathrm{h}$ to $5.5 \mathrm{~g} / \mathrm{m}^{2} \cdot \mathrm{h}$, with an average of 1.6 $241 \mathrm{~g} / \mathrm{m}^{2} \cdot \mathrm{h}$. These values were comparable to those obtained with Dermalab ${ }^{\circledR}$ and confirmed the 242 reliability of the sweat rate sensor.

243 The comparison between our sensor and Dermalab ${ }^{\circledR}$ was also made by the Bland-Altman plot [29, 244 30]. The plot was constructed by the medical and statistical tool MedCalc (MedCalc ${ }^{\circledR}$ Software). 245 Figures $7 \mathrm{a}$ and $7 \mathrm{~b}$ show the Bland-Altman plot for Phase 1 and 2, respectively. The statistical 246 results are shown in Table 1. In Phase 1 the plot in Fig. 7a and the corresponding column in Table 1 247 exactly confirm the results reported for Fig. 6a, i.e. an acceptable average difference in the basal 248 values of $3.4 \mathrm{~g} / \mathrm{m}^{2} \cdot \mathrm{h}$ with a standard deviation of $7.6 \mathrm{~g} / \mathrm{m}^{2} \cdot \mathrm{h}$. As $95 \%$ of points fall in the interval 249 between the upper and lower limits $(11.5,-18.3)$, the data are normally distributed. In Phase 2, the 250 plot in Fig. $7 \mathrm{~b}$ and corresponding column in Table 1 show a bias of $2.3 \mathrm{~g} / \mathrm{m}^{2} \cdot \mathrm{h}$ and a standard 251 deviation of $6.9 \mathrm{~g} / \mathrm{m}^{2} \cdot \mathrm{h}$, roughly. The bias is even better than that obtained from Fig. $6 \mathrm{~b}$, whereas 252 the standard deviation is close.

253 Furthermore, the P-values for both plots ( 0.1331 and 0.2477 obtained by Kolmogorov-Smirnov test) 254 allow the hypothesis that there is a significant difference between the two distributions, thus 255 between the Dermalab and our sweat rate sensor, to be rejected. 


\section{Discussion}

259 The statistical analysis proved that the sensor was capable of real-time monitoring sweat rate in a 260 localized area of the human body. Previous approaches were mainly based on indirect 261 measurements by means of gravimetrical techniques [22]. Our sensor can pave the way for 262 distributed body network capable of monitoring different body areas. This network may give 263 valuable information on the hydration level so that athletes can personalize trainings and improve 264 their physical performances. It could also lead to a biofeedback system, which is a field that is 265 gaining increasing consensus in the sport domain [31]. For example, in a similar test on an 266 ergometer, Vimieiro-Gomes et al. found that the whole-body sweat rate and the local sweat rate on 267 the forearm are correlated [32]. Since the amount of sweat excreted by human body is proportional 268 to that excreted by the forearm, they suggest that the measurement of forearm sweat rate may be 269 used to estimate the whole-body sweat rate. Therefore, in future works, our sensor could also give 270 valuable information on the overall sweat loss.

271 However, the sensor still needs to be further tested in a non-controlled environment where fast air 272 movements and humidity could affect the measurement as they modify the evaporation rate. In our 273 next version of the sensor, we plan to adopt a configuration that can be integrated directly into 274 garments to increase the comfort for the user, and to add a Bluetooth ${ }^{\circledR}$ module for monitoring the 275 sweat rate via a smartphone.

\section{Conclusion}

279

280 We presented a prototype of a wearable sweat rate sensor for localized measurements. The trials on 281 thirteen athletes proved that the performance of our sensor was comparable to that of a commercial 282 device that, although not measuring the sweat rate, is based on the same measurement principle. 283 The differences were negligible, especially at maximum sweat rates. Our sensor is lightweight and 284 can be worn on the body. The logging system can be inserted into a small phone bag and worn, for 285 example, on an arm or on the waist. Future study will include the simultaneous measurement of 286 sweat rate in different body areas and the development of an algorithm capable of estimating the 287 global sweat rate while the user is in uncontrolled environment. 
289 Acknowledgements

290

291 The authors would like to thank Dr. Shirley Coyle (Dublin City University) for the help given with 292 the 3D printed adapter.

293

294

295 Funding

296

297 298

299

300 Declaration of conflicting interests

301

302

The authors declare that there is no conflict of interests.

303

304

305

References

306

307

308

309

310

311

312

313

314

315

316

1. Lim CL, Byrne $\mathrm{C}$ and Lee JKW. Human Thermoregulation and Measurement of Body Temperature in Exercise and Clinical Settings. Ann Acad Med 2008; 37: 347-53.

2. Kondo N, Shibasaki M, Aoki K, et al. Function of human eccrine sweat glands during dynamic exercise and passive heat stress. J Appl Physiol 2001; 90: 1877-1881.

3. Salvo P. Sweat rate wearable sensors. In: Iniewski K (ed) Biological and medical sensor technologies, Boca Raton: CRC Press, 2012, pp. 243-262.

4. Sato K and Sato F. Individual variations in structure and function of human eccrine sweat gland. Am J Physiol 1983; 245: 203-208.

5. Armstrong LE, Hubbard RW, Jones BH, et al. Preparing Alberto Salazar for the heat of the 1984 olympic marathon. Phys Sportsme 1986; 14: 73-81. 
6. Robinson S and Robinson AH. Chemical composition of sweat. Physiol Rev 1954; 34: 202220.

7. Fellmann N. Hydration of athletic riders. Sci Sport, 1993; 8(2): 93-100.

8. Maughan RJ, Shirreffs SM. Rehydration and recovery after exercise. Sci Sport, 2004; 19(5): 234-238.

9. Brotherhood JR. Nutrition and sports performance. Sports Med 1984; 1: 350-389.

10. Casa DJ, Armstrong LE, Hillman SK, et al. National Athletic Trainers' Association Position Statement: Fluid Replacement for Athletes. J Athl Train 2000; 35: 212-224.

11. WHO. Guideline: Sodium intake for adults and children. World Health Organization (WHO) 2012, Geneve, Switzerland.

12. Boegehold MA and Kotchen TA. Importance of dietary chloride for salt sensitivity of blood pressure. Hypertension 1991; 17: I158-I161.

13. Clausen MJV and Poulsen H. Sodium/Potassium Homeostasis in the Cell. Met Ions Life Sci 2013; 12: 41-67.

14. Coyle S, Morris D, Lau KT, et al. Textile sensors to measure sweat $\mathrm{pH}$ and sweat-rate during exercise. In: IEEE Conference on Pervasive Computing, London, United Kingdom, 1-3 April 2009, pp. 1 - 6.

15. Sato KT, Richardson A, Timm DE, et al. One-step iodine starch method for direct visualization of sweating. Am J Med Sci 1988; 6: 528-531.

16. Shirreffs SM and Maughan RJ. Whole body sweat collection in humans: an improved method with preliminary data on electrolyte content. J Appl Physiol 1997; 82: 336-341.

17. Tronstad C, Gjein GE, Grimnes S, et al. Electrical measurement of sweat activity. Physiol Meas 2008; 29: S407-S415.

18. Zhang B and Cui T. High-performance and low-cost ion sensitive sensor array based on self-assembled graphene. Sens Actuators A-Phys 2012; 177: 110-114.

19. Massie J, Gaskin K, Van Asperen P, et al. Sweat testing following newborn screening for cystic fibrosis. Pediatr Pulmonol 2000; 29: 452-456.

20. Altemus M, Rao B, Dhabhar FS, et al. Stress-Induced Changes in Skin Barrier Function in Healthy Women. J Invest Dermatol 2001; 117: 309-317.

21. Kintz P, Tracqui A and Mangin P. Sweat Testing in Opioid Users with a Sweat Patch. J Anal Toxicol 1996; 20: 393-397.

22. Matzeu G, Fay C, Vaillant A, Coyle S, Diamond D. A wearable device for monitoring sweat rates via image analysis. IEEE Trans Biomed Eng. 2015; 63(8): 1672-1680. 
350 23. Salvo P, Di Francesco F, Costanzo D, et al. A wearable sensor for measuring sweat rate. $351 \quad$ IEEE Sens J 2010; 10: 1557-1558.

352 24. Nilsson GE. Measurement of water exchange through skin. Med Biol Eng Comput 1977; 15: $353 \quad 209-218$.

354 25. Salvo P, Dini V, Di Francesco F, Romanelli M. The role of biomedical sensors in wound 355 healing. Wound Medicine 2015; 8: 15-18.

356 26. Salvo P, Melai B, Calisi N, et al. Current technology and advances in transepidermal water 357 loss sensors. In: Karlen W (ed.) Mobile Point-of-Care Monitors and Diagnostic Device 358 Design. Boca Raton: CRC Press, 2014, 63-78.

359 27. Cohen JC, Hartman DG, Garofalo MJ, et al. Comparison of closed chamber and open 360 chamber evaporimetry. Skin Res Technol 2009; 15(1): 51-54.

361 28. Gee RM, Bell SA, Imhof RE, et al. TEWL Calibration Consortium. Uncertainty Analysis for 362 the Droplet Method of Water Vapour Flux Calibration. In: $5^{\text {th }}$ International Symposium on 363 Humidity and Moisture, Rio de Janeiro, Brazil, 02-05 May, 2006.

364 29. Altman DG, Bland JM. Measurement in medicine: The analysis of method comparison $365 \quad$ studies. The Statistician 1983; 32:307-317.

366 30. Bland JM, Altman DG. Statistical methods for assessing agreement between two methods of 367 clinical measurement. Lancet 1986; 1:307-310.

368 31. Alahakone AU and Senanayake A. A real-time interactive biofeedback system for sports 369 training and rehabilitation. Proc Inst Mech Eng, Part P: J Sports Eng Technol 2010; 224: 370 181-190.

32. Vimieiro-Gomes AC, Magalhães FC, Amorim FT, Machado-Moreira CA, Rosa MS, Lima 373 $\mathrm{NR}$, et al. Comparison of sweat rate during graded exercise and the local rate induced by pilocarpine. Braz J Med Biol Res. 2005; 38(7):1133-9. 


\title{
Reply to Reviewers' Comments
}

\author{
Manuscript SCISPO-D-16-00011
}

\begin{abstract}
We thank the reviewers for their comments that helped us to improve the quality of our paper. We hope that our revision will meet their expectations in order to be accepted for publication in Science \& Sports.
\end{abstract}

\section{Reviewer \#1:}

Major comments.

1) What is the rationale of measuring local sweat rates to monitor fluid and electrolyte loss, while they vary with localization and between individuals. Whether measuring global sweat rates during exercise would be more efficient than voluntary drinking, especially for monitoring the replacement of fluid losses needs to be strengthened.

- Reply: we acknowledge the reviewer for this question. An established reference technique capable of accurately estimating sweat rate variations over time is still undefined. As pointed out in the Introduction, the whole body wash down method can only be carried out in strictly controlled lab conditions, where volunteers cycle in an environment enclosed by "plastic bags". Other attempts foresee localised sweat sampling using absorbent patches positioned in specific locations (e.g. forearm, thigh, back, and calf). The sweat rates were determined gravimetrically by weighting syringes that aspirated the collected sweat from patches or after weighting the entire patches. Despite the simplicity of this approach, such patches can affect sweat rates by causing sweat pools on skin surfaces, suppressing the evaporation of the fluid at the collection sites, and increasing local skin temperature.

A possible solution is the development of wearable sensors that can be worn in different parts of the body and the estimation of the global sweat rate by evaluating the resulting data with a proper algorithm.

Presently, this research is at the stage of the sensor development. For example, some smartwatch producers locally measure the galvanic skin resistance and try (with poor results yet) to estimate sweat rate.

Our sensors follows this research path and we believe that it is a more practical and efficient solution than the sensors described in reference 22 or than the galvanic skin resistance.

We agree with the reviewer concerning the large variations between individuals, and that is why the development of a future algorithm to estimate the global sweat rate is crucial.

We modified both the Introduction and the Conclusions to discuss this concept more in depth.

2) Lines 130-131 (and lines 4-6). What is the precise and exact objective of this study?

- Reply: we think that part of the answer is given in the reply to the first reviewer's comment. We follow the current research path towards the development of a wearable sensor capable to measure sweat rate in multiple body areas when the user is outside controlled labs. The second step is the development of an algorithm to estimate the global sweat rate. We modified the Summary, Introduction, and the Conclusion. 
3) Line 203-204. What means "maximum values" for sweating rates? Was the aim of the exercise to measure maximal sweating rate? Are you sure that using such exercise protocol, the maximal sweat rate was reached at functional exhaustion?

- Reply: We thank you the reviewer for this comment. We modified the test to highlight that we measure the sweat rate till the subject reached functional exhaustion.

4) Were maximal sweating rate values measured at the end of cycling exercise in the range of fluid losses recorded in athletes during exercise in the field? As a consequence, was the present experimental protocol able to conclude on the accuracy of measures for high sweating rate values?

- Reply: The maximum sweat rate values were observed at the maximum ergometer load and we added this information in the text. Although not reported in the paper, we weighted the volunteers before and after the test and integrated the sweat rate profile to check the reliability of the sensor and we found a good agreement with the weight loss.

5) What is the rationale to select Dermalab® as the reference device.

- Reply: As pointed out in the Introduction, the research on wearable sweat rate sensor is at the early stage of development. We decided to use as a reference a device that a) is commercially available and clinically validated and b) exactly works on the same openchamber method used in our sensors (thus the results are the closest comparable with our sensor). As reported in the previous reply, we checked the reliability of this sensor for our purpose.

We modified the text to describe better the use of Dermalab.

6) Where both experimental sensor and Dermalab® have been set up on the body?

- Reply: The Dermalab is not a wearable device as reported in the Introduction and Figure 4. However, the reviewer is right because the text was definitely not clear. We modified the text to avoid any confusion.

7) Were the measures of local sweat rates representative of global sweat rate? How to translate values of local sweat rates on body fluid loss?

- Reply: We think that the answer given to the first comment and the consequent modification in the Introduction and Conclusion should address this comment.

8) Lines 268-270. What means "lactate"? Blood lactate concentrations? If true, there are only weak correlations between blood lactate and anaerobic threshold, and the information given by sweat rates on anaerobic threshold is far too weak.

- Reply: the reviewer is right. We relied on the information reported in reference 22, but we have now deleted this sentence from the text. 
1) Lines 34-35, 131, 266-267. Could this wearable sensor be used to "improve" or "maintain" physical performances? On the other hand this sentence could be viewed as a field application of the tool, while its accuracy, repeatability and global performances remain to be proved.

- Reply: We modified the Summary, Introduction and Conclusion after the major comments 1) and 2). We think that the answers given to those comments and the modifications in the text better explain the objective of our paper.

2) Line 70. It is the rate of sweat production that depends from the "emitted amount per gland".

- Reply: the reviewer is right and we corrected the text accordingly.

3) Line 71. What means the absolute number of glands?

- Reply: We are not sure to have correctly understood the reviewer's comment. However, in line 71 we have only reported that the number of eccrine glands is known to be in the range $[1.6,4]$ million as in reference 3 .

4) Line 85. There is a wide range of injuries and acute events associated with hyperthermia between heat cramps and heatstroke (Bouchama, NEJM, 1978).

- Reply: we modified the text to indicate that we only reported some examples of negative events associated with dehydration.

5) Lines 198-208. Should be moved in Material and Methods.

- Reply: We moved the paragraph describing the test and Dermalab in Material and methods as requested from the reviewer. 


\section{Figure captions}

Figure 1. a) 3D printed adapter (in black) with the PTFE chamber and the Velcro ${ }^{\circledR}$ strips. The cut through the adapter and the chamber allows the electronic board to be inserted to measure the sweat rate; b) enlarged detail of the adapter. The base is thicker at the extremities to fit better the curvature body surface.

Figure 2. Printed circuit board with the humidity and temperature sensors (SHT25) and the I2C switch. The centres of the SHT25s are at 4 and $11 \mathrm{~mm}$ from the bottom of the board, respectively.

Figure 3. The sweat rate sensor worn of the arm of a volunteer. The read-out electronics is inserted into the smartphone-like bag equipped with Velcro ${ }^{\circledR}$ strips. The bag can be worn elsewhere, e.g. the waist, by adjusting the cable length.

Figure 4. Calibration curve for the sweat rate sensor (log-log scale). The sensor response is linear until a sweat rate of $200 \mathrm{~g} / \mathrm{m}^{2} \cdot \mathrm{h}$.

Figure 5. Example of a measurement using the Dermalab ${ }^{\circledR}$ equipped with the TEWL probe.

Figure 6. a) Comparison of the sweat rate base values between the Dermalab ${ }^{\circledR}$ and the wearable sensor during the cycling tests; b) Comparison of the sweat rate maximum values between the Dermalab $^{\circledR}$ and the wearable sensor during the cycling tests; c) Typical result of cycling test. Phase 1 is associated with the sweat rate base value. In Phase 2, the volunteers reached the maximum sweat rate. The volunteers stopped cycling approximately one minute before the end of this phase. In Phase 3, the sweat rate returned to the base value; d) Repeatability of the sweat rate sensor. The standard deviations for Dermalab ${ }^{\circledR}$ and the sweat rate sensor are calculated in Phase 1 where the sweat rate base values for the football players can be assumed constant.

Figure 7. a) Bland-Altman plot associated with Phase 1 (base values) using a comparison of sweat rate $\left(\mathrm{g} / \mathrm{m}^{2} \cdot \mathrm{h}\right)$ obtained with Dermalab ${ }^{\circledR}$ and the sweat rate sensor described in this paper; b) BlandAltman plot associated with Phase 2 (maximum values) using a comparison of sweat rate $\left(\mathrm{g} / \mathrm{m}^{2} \cdot \mathrm{h}\right.$ ) obtained with Dermalab ${ }^{\circledR}$ and the sweat rate sensor described in this paper. 
Click here to download high resolution image

\section{PTFE chamber}

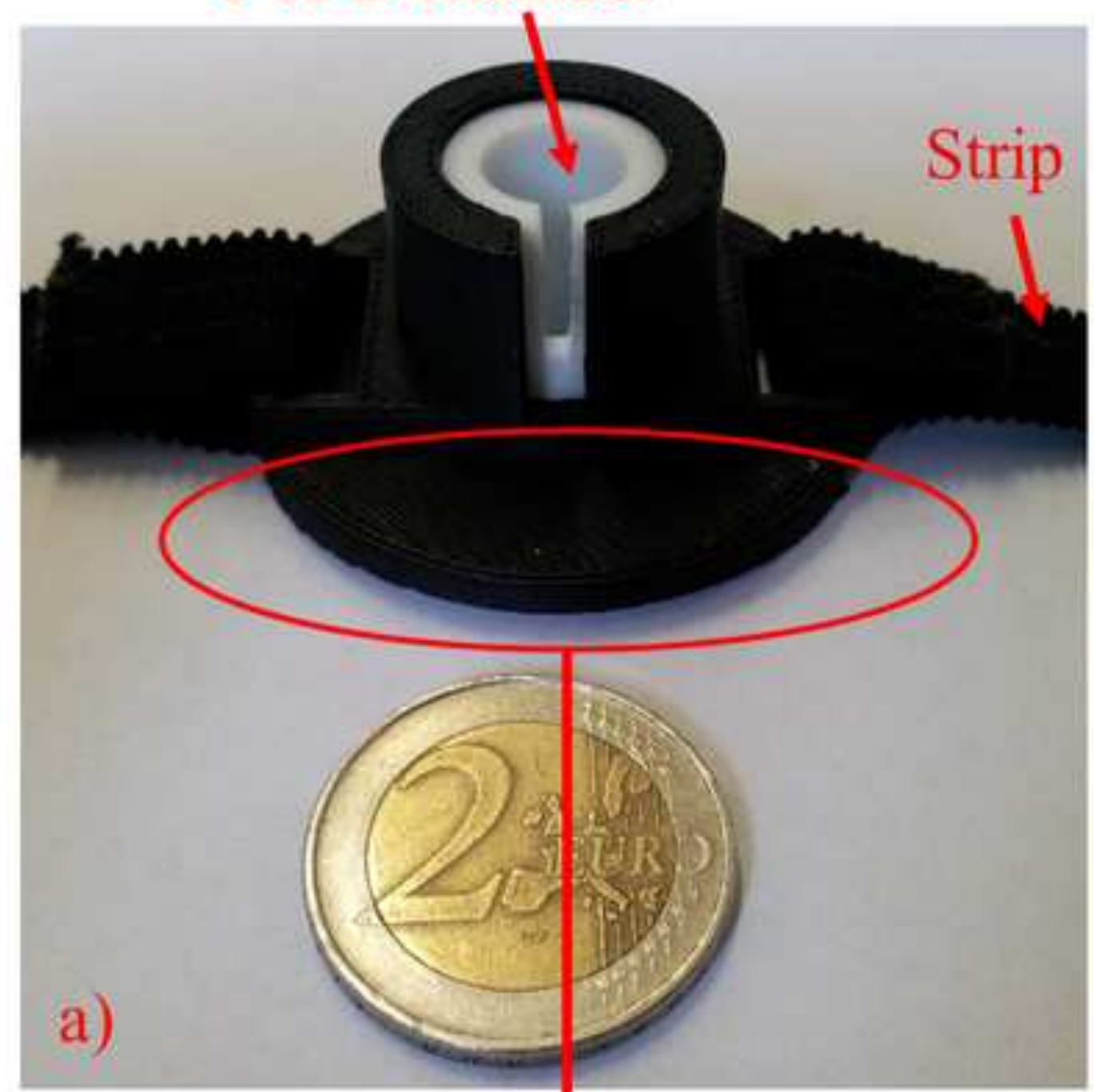

\section{กากต}

b) 
Click here to download high resolution image

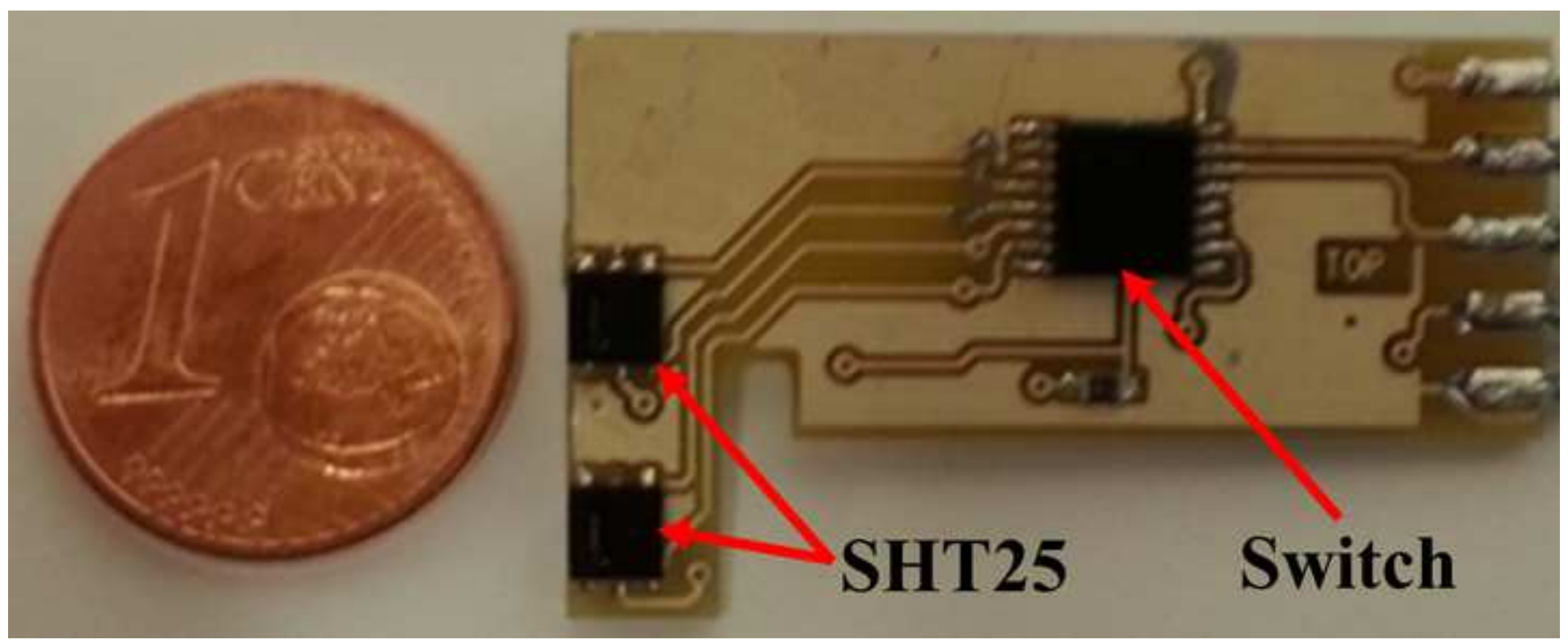


Click here to download high resolution image

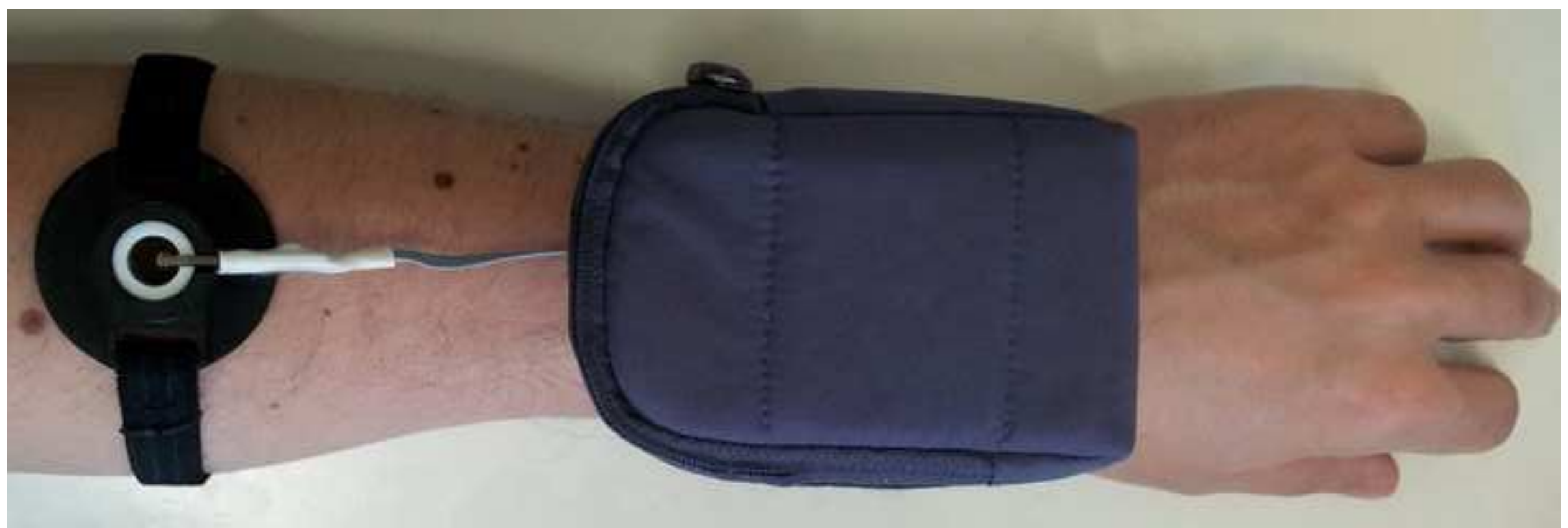


Click here to download high resolution image

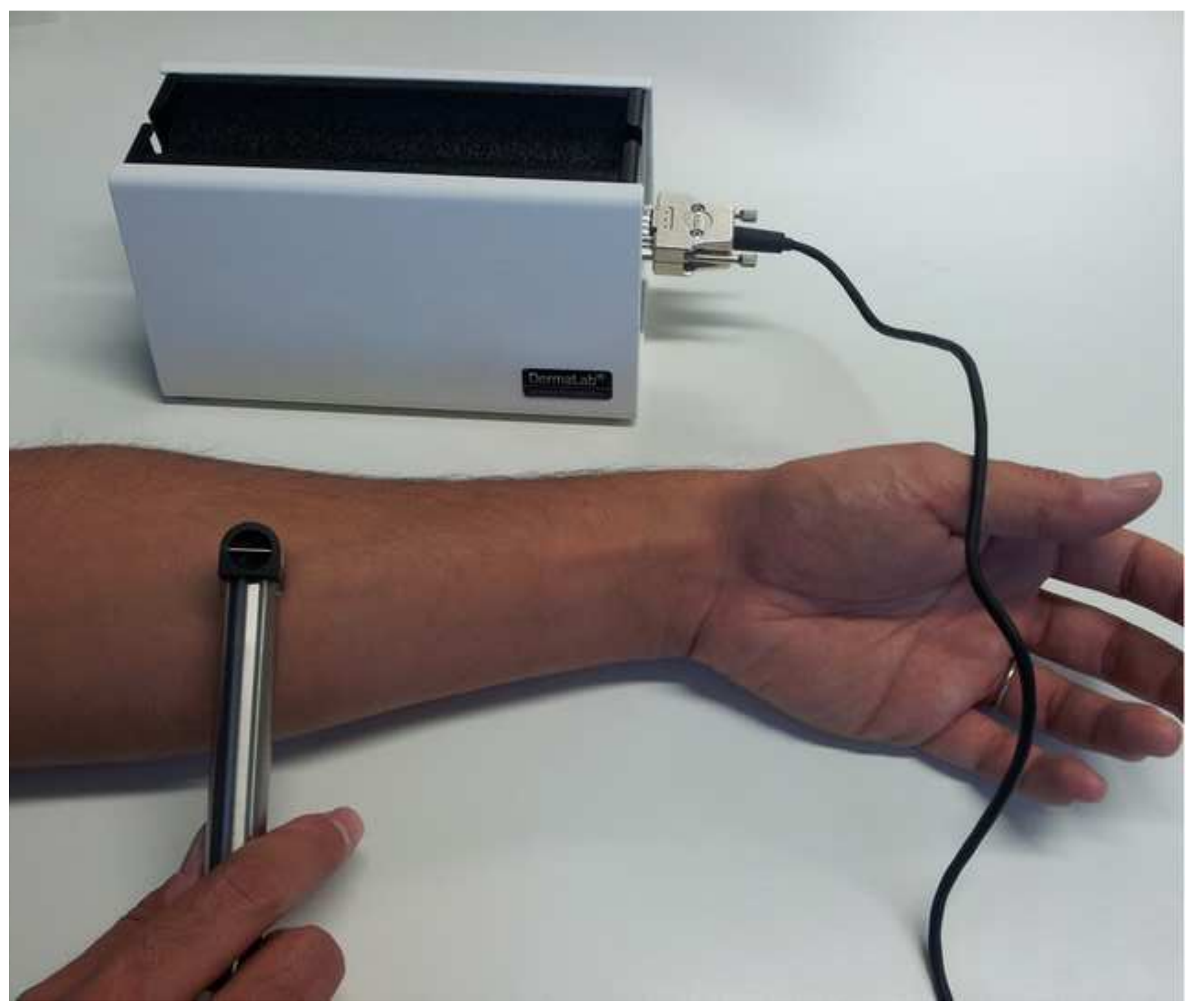


Figure 5

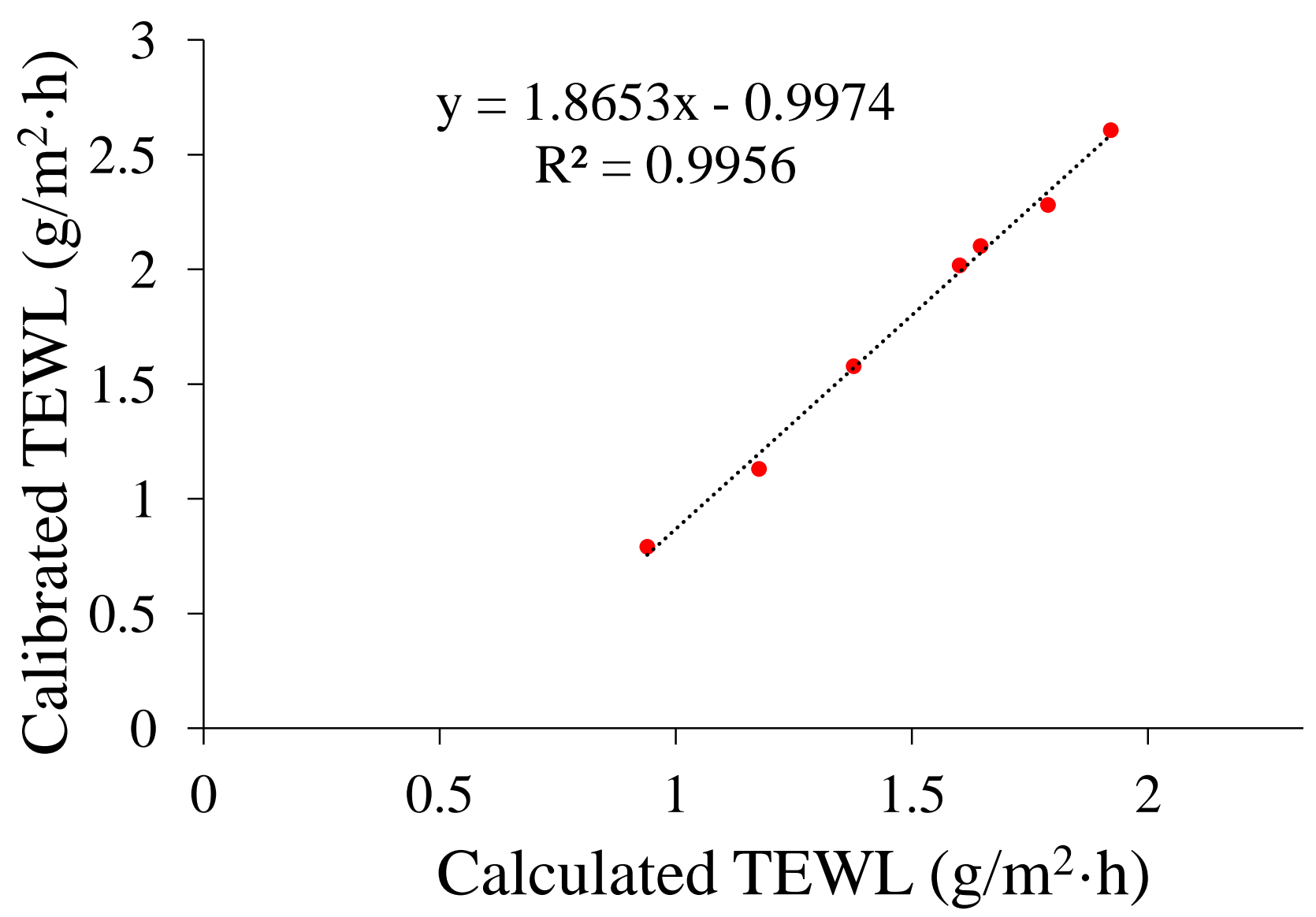



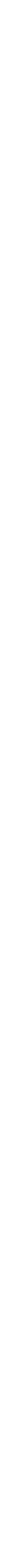

Phase 1

Phase 2

Phase 3

b) 
a)

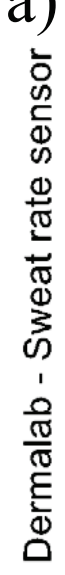

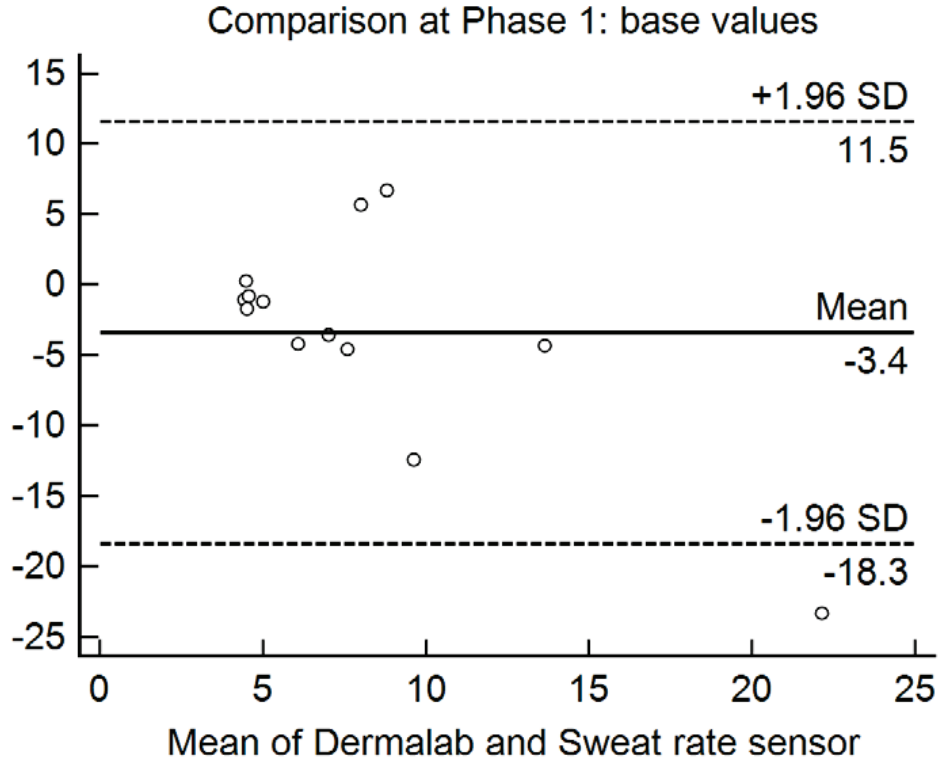

b)

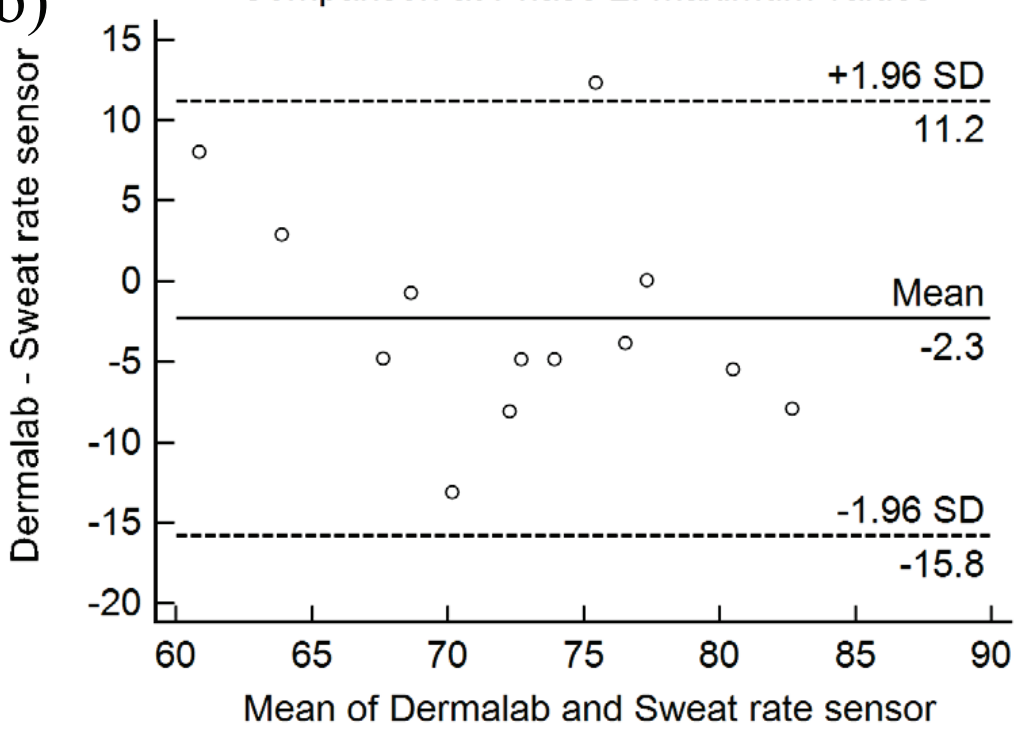




\section{Tables}

Table 1. Statistical results obtained by MedCalc associated with the Bland-Altman plots for the Dermalab and the sweat rate sensor at Phase 1 and Phase 2.

\begin{tabular}{ccc}
\hline Results & Comparison at Phase 1 & Comparison at Phase 2 \\
\hline Arithmetic mean & -3.4069 & -2.3192 \\
$95 \%$ Confidence Interval & -8.0135 to 1.1997 & -6.4782 to 1.8398 \\
\hline $\mathrm{P}\left(\mathrm{H}_{0}\right.$ : Mean=0) & 0.1331 & 0.2477 \\
\hline Standard deviation & 7.6231 & -15.8087 \\
Lower limit & -18.3482 & -23.1087 to -8.5087 \\
95\% Confidence Interval & -26.4339 to -10.2625 & 11.1702 \\
\hline Upper limit & 11.5344 & 3.8702 to 18.4703 \\
\hline 95\% Confidence Interval & 3.4487 to 19.6201 & \\
\hline
\end{tabular}

